\title{
EFFICACY EVALUATION OF THE PHYTOTHERAPEUTIC DRUG CANEPHRON N IN THE COMPLEX TREATMENT OF PATIENTS WITH UROLITHIASIS USING EXTRACORPOREAL SHOCK WAVE LITHOTRIPSY
}

\author{
Volodymir Vitkovskyy \\ Department of the Lithotripsy \\ Lviv Regional Hospital \\ 7 Chernigivska str., Lviv, Ukraine, 79010 \\ V.vitkovskyy@gmail.com
}

\begin{abstract}
The study objective was to analyse the effect of the herbal drug Canephron N, namely, its ability to potentiate the efficacy of extracorporeal shock wave lithotripsy (ESWL) in the treatment of patients with urolithiasis (UL) and prevent recurrence of stone formation.

Aim. To check the hypothesis that treatment with Canephron $\mathrm{N}$ can potentiate lithotripsy and reduce the risk of re-stone formation.

Methodology. Patients at the age of 18 to 65 years had calcium oxalate urolithiasis with the size of the stone from 0.8 to $1.3 \mathrm{~cm}$ in the kidneys and from 0.5 to $0.9 \mathrm{~cm}$. in ureters who underwent ESWL procedure. They were randomized into 2 equal groups of 30 people. The treatment group received general recommendations on the management of the patient with UL following ESWL and the herbal drug Canephron $\mathrm{N}$ for 6 months. The control group received only general recommendations. Moreover, according to condition, both groups received painkillers and spasmolytics if pain occurred during elimination of fragments. The following parameters were evaluated: the period of elimination of fragments after stone disintegration by ESWL method; the percentage of complete elimination of fragments; the presence of pain syndrome and leukocyturia in the postoperative period; the rate of recurrence of stone formation during one year after the procedure.

Results. More complete and rapid elimination of fragments was observed in the treatment group. Thus, up to day 14 elimination of stone fragments was observed in $96.6 \%$ of patients in the treatment group versus $76.6 \%$ in the control group. Fewer cases of pain syndrome during elimination of stone fragments ( $23 \%$ in the treatment group and $43 \%$ in the control group) and rare cases of leukocyturia within 14 days (10\% versus $23 \%$, respectively) were observed in the treatment group. Recurrent stone formation within the year was not observed in patients of the treatment group, in the control group - in $23 \%$ of patients. However, because of the small size of the groups, one may talk about a tendency but not about statistically significant patterns.

Conclusion. Canephron $\mathrm{N}$ is an effective and safe drug in the treatment of patients with urolithiasis who underwent extracorporeal shock wave lithotripsy. Its use contributes to more rapid and safe elimination of fragments of destructed calculi and reduces risk of recurrent stone formation.
\end{abstract}

Keywords: urolithiasis, shock wave lithotripsy, Canephron N, elimination of fragments, recurrence, ultrasound investigation.

\section{Introduction}

Urolithiasis (UL) is a metabolic disease caused by a variety of endogenous and/or exogenous factors; it is often hereditary and characterized by stone formation in the urinary system [1]. Despite major advances in early diagnosing and treatment of patients with UL $[2,3]$, the patient stream to hospitals is only increased [4] every year due to the lack of consistency between the inpatient and outpatient urological services. Moreover, the development of metaphylaxis methods of recurrent stone formation falls far behind the introduction of new methods of calculi removal from the urinary tracts. This tendency is the least efficient from economic point of view because the mechanical stone removal does not solve the problems of metabolic disorders that lead to stone formation. The recurrence rate of urolithiasis after removing calculi is $30 \%$. Therefore, economic aspects are important and discussed at present $[1,3]$.

Extracorporeal shock wave lithotripsy (ESWL) is one of the main methods of treatment of urolithiasis in Ukraine, which provides elimination of urinary tract calculi in most patients. At the same time, the process of elimination of destructed urinary tract calculi takes time; there is 
also a risk of their incomplete elimination. In addition, even in the event of complete and uncomplicated elimination of urinary calculi $[5,6]$, there is a significantly increased risk of recurrence of stone formation in the following years. It means that the method of elimination of urinary tract stones does not affect the metabolic disorders, which manifest themselves as calculi formation. Thus, there is a need for accompanying therapy, which can improve efficacy of elimination of calculi following ESWL on the one hand and reduce the likelihood of recurrence in a long-term therapy on the other hand [7,8]. The herbal drug Canephron $\mathrm{N}$ has a complex of effects that may affect both the efficacy of elimination of urinary calculi fragments following lithotripsy $[5,9]$ and non-specific factors of stone formation: decrease in urinary saturation by stone-forming substances; increase in concentration of magnesium ions in urine which are natural inhibitors of crystallization [10]; effect on indirect factors of calculi formation (inflammation, impaired urodynamics, etc.).

At this time, there is considerable experience in using Canephron $\mathrm{N}$ both in treatment and metaphylaxis of urolithiasis $[11,12]$. However, there is a limited number of studies where the ability of Canephron N to potentiate ESWL effect and prevent the risk of UL recurrence was evaluated.

\section{Aim of research}

Analyse the ability of the drug Canephron $\mathrm{N}$ to potentiate the efficacy of extracorporeal shock wave lithotripsy in the treatment of patients with UL and prevent recurrent stone formation in the first year after complete elimination of fragments in these patients.

\section{Materials and methods}

Study design: our study was an open, single centre, prospective, comparative (parallel group), interventional randomized study. To achieve the objective we selected two groups of 30 patients with UL (at the age of 18 to 65 years) with diagnosed calcium oxalate urolithiasis, existing single stones relatively of the same size localized in the kidneys and ureters. The study compared treatment with the drug Canephron $\mathrm{N}$ (treatment group) in combination with traditional treatment in patients with UL by ESWL method and patients (control group) who received only the traditional UL treatment by ESWL method (Table 1).

Table 1

Treatment groups during the study for 6 months

\begin{tabular}{|c|c|c|c|}
\hline Group & Medical treatment & Dosage & Duration \\
\hline \multirow{7}{*}{$\begin{array}{l}\text { Treatment group } \\
\qquad(\mathrm{n}=30)\end{array}$} & ESWL & 1 ESWL session & Single time \\
\hline & Diet & & Kept \\
\hline & Adequate fluid intake & & Kept \\
\hline & Canephron $\mathrm{N}$ & $\begin{array}{l}2 \text { tablets } / 50 \text { drops } \\
3 \text { times daily }\end{array}$ & 6 month \\
\hline & Spasmolytics & As prescribed & $\begin{array}{l}\text { During the period of } \\
\text { elimination of fragments }\end{array}$ \\
\hline & PT & Daily & Daily \\
\hline & $\begin{array}{l}\text { Painkillers, spasmolytics } \\
\text { if pain syndrome occurs }\end{array}$ & As prescribed & Situationally Single time \\
\hline \multirow{6}{*}{$\begin{array}{l}\text { Control group } \\
\qquad(\mathrm{n}=30)\end{array}$} & ESWL & 1 ESWL session & Single time \\
\hline & Diet & & Kept \\
\hline & Adequate fluid intake & & Kept \\
\hline & Spasmolytics & As prescribed & $\begin{array}{l}\text { During the period of elimina- } \\
\text { tion of fragments }\end{array}$ \\
\hline & PT & Daily & Daily \\
\hline & $\begin{array}{c}\text { Painkillers, spasmolytics if } \\
\text { pain syndrome occurs }\end{array}$ & As directed & Situationally Single time \\
\hline
\end{tabular}


According to the standard of care, all patients underwent a complete urological examination before treatment initiation: complete blood count, urinalysis with microscopy, urine $\mathrm{pH}$ testing (before, during and after the treatment); blood biochemistry; plain urography (+ after the treatment); ultrasonography of kidneys, ureters and the bladder (before, during and after the treatment).

\section{Study population:}

Patients (men and women) from 18 to 65 years (the average age was 41.5 years) with diagnosed UL (calcium oxalate urolithiasis) following ESWL - 60 patients with stones relatively of the same size and location and preserved kidney function. The treatment and control groups consisted of 30 patients each $(n=30)$. The distribution between the groups was performed by randomly numbered envelopes.

Inclusion criteria: The main inclusion criterion was a proven diagnosis of calcium oxalate urolithiasis with a single stone from 0.8 to $1.3 \mathrm{~cm}$ in size in the kidneys and a single stone from $0.5 \mathrm{~cm}$ to $0.9 \mathrm{~cm}$ in the ureter; age of $18-65$ years and consent to participate in the study. The chemical composition of the calculus was predicted with urine microscopy, urine $\mathrm{pH}$ test and plain X-ray before treatment and with X-ray structural analysis after elimination of fragments.

\section{Exclusion criteria:}

- Generally accepted contraindications to treatment with ESWL method;

- Long-term urinary tract obstruction by a stone and marked impairment of excretory function of the kidneys;

- Diabetes mellitus;

- Immunodeficiency;

- Severe concomitant somatic disease that may significantly affect the course of UL treatment with ESWL method;

- Calculus size greater than $1.3 \mathrm{~cm}$;

- Chemically another type of urolithiasis (phosphates, urates, struvites).

\section{Study methodology}

During the study period patients had 6 visits: visit 1 (Day 1) - ESWL procedure; visit 2 (Day 7) - evaluation of elimination results of disintegrated calculi; no complications and indications for repeat procedure; visit 3 (Day 14) - evaluation of treatment results (percentage of compete elimination of the urinary tract fragments of the disintegrated stone; no complications); visit 4 (Day 30) - evaluation of treatment results (percentage of complete elimination of the urinary tract fragments); visit 5 (Day 45) - final evaluation of treatment results (percentage of complete elimination of the urinary tract fragments); visit 6 (one year after) - evaluation of possible recurrence of stone formation.

From visit 1 to visit 6 the doctor evaluated:

- complaints, pain localization, severity, discomfort, urination disorders and other;

- clinical and physical examination results;

- results of complete blood count;

- results of urinalysis: urine $\mathrm{pH}$ test, level of leukocyturia;

- results of ultrasound of kidneys, ureters, bladder;

- plain X-ray results (if necessary).

\section{Efficacy endpoints}

The main efficacy endpoints were included complete elimination of the urinary tract calculi and their fragments, the need for repeat ESWL, no complications and no disease recurrence within one year.

\section{Safety criteria}

No side or adverse events during the study drug administration. 


\section{Data analysis}

Data were presented using descriptive methods. The difference between two groups was evaluated with the help of two samples using a two-sided $95 \%$ confidence interval $(95 \% \mathrm{CI})$ with a confidence coefficient of $\mathrm{p} \leq 0.05$.

\section{Results}

The average age of the patients in the treatment group was $41( \pm 4.6)$ years; in the control group - $42( \pm 5.0)$ years. This means that the groups did not have any age differences. In the treatment group $33.3 \%$ of patients had calculi in the renal pelvis, $16.7 \%$ in the renal calyx, $33.3 \%$ in the proximal ureter and $6.7 \%$ of patients in the distal ureter. The average size of stones in the kidneys was $1.0 \pm 0.2 \mathrm{~cm} ; 0.7 \pm 0.1 \mathrm{~cm}$ in the ureters. In the control group, stones in the renal pelvis were detected in $30 \%$ of patients; in the renal calyx - in $20 \%$ of patients. Calculi in the proximal ureter were detected in $36.7 \%$ of patients; in the distal ureter - in $13.3 \%$ of patients. The average size of renal calculi was $1.0 \pm 0.3 \mathrm{~cm}$, ureteral calculi $-0.7 \pm 0.2 \mathrm{~cm}$. Before treatment starts, lumbar pain (localization of calculus) was observed in $83.3 \%$ of patients in the treatment group and in $80 \%$ of patients in the control group. Leukocyturia was also observed in $40 \%$ and $33 \%$ of patients, respectively. Urine $\mathrm{pH}$ in the treatment group was $5.9 \pm 0.5$; in the control group $-6.0 \pm 0.5$. All the patients of both groups successfully underwent 34 and 35 ESWL sessions, respectively; the average number of impulses necessary for stone fragmentation was $2450 \pm 350$ (in the treatment group) and $2450 \pm 400$ (in the control group). Stone disintegration following ESWL session was successful if there were fragments up to $4 \mathrm{~mm}$, which were evaluated with the control ultrasound investigation and plain Xray examination, if necessary.

\section{Elimination of destructed fragments.}

During the follow-up there was a significant difference in the dynamics of elimination of destructed urinary calculi. This parameter is depicted in Fig. 1.

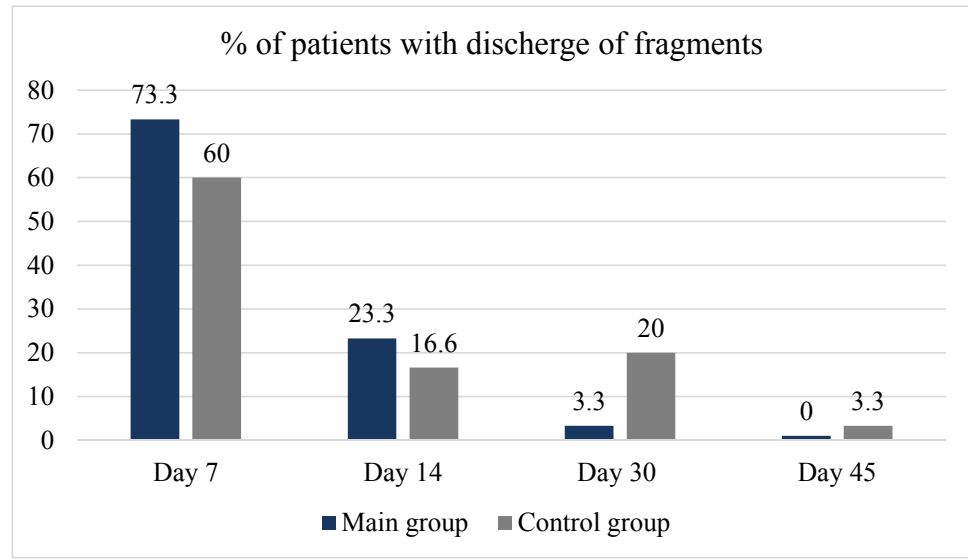

Fig. 1. Dynamics (\%) of elimination of destructed urinary stones in the groups.

Despite the fact that in our study the complete elimination of destructed stone fragments was observed in all patients in both groups, we may conclude that this process was much faster in the treatment group. Thus, the complete elimination of fragments from the urinary tracts after 14 days was $96.7 \%$ in the treatment group. Only one patient $(3.3 \%)$ needed a longer period (up to 30 days) for elimination of destructed fragments. After 14 days, the complete elimination of fragments was observed only in $76.6 \%$ of patients in the control group, almost $20 \%$ less than in the treatment group.

In order to achieve the complete elimination of calculi, some patients needed repeated ESWL sessions because of the large fragments determined by ultrasound and X-ray examinations. Thus, the average number of EL sessions per one stone in the treatment and control groups was 
1.13 and 1.17 sessions, respectively. However, this difference was not statistically significant and had the character of a tendency.

\section{Complications following ESWL}

After the EWSL procedure during elimination of urinary calculi fragments, some patients had lumbar pain, which in some cases had the character of renal colic. It is important to note that some of these complications was significantly lower in the treatment group compared with the control group in relation to the "pain and discomfort" symptom and leukocyturia. In regard to renal colic there was also a difference but it was not statistically significant and had the character of a tendency (Table 2).

Table 2

Proportion of complications following ESWL in the groups during elimination of stone fragments

\begin{tabular}{ccccc}
\hline No. & Symptoms & Treatment group n/\% & Control group n/ \% & Power \\
\hline 1 & $\begin{array}{c}\text { Lumbar pain during fragment elimination, } \\
\text { lower abdominal pain. }\end{array}$ & $7(23 \%)$ & $13(43.3 \%)$ & $\mathrm{p} \leq 0.05$ \\
2 & Renal colic & $2(6.6 \%)$ & $3(10 \%)$ & $\mathrm{p} \leq 0.05$ \\
3 & Leukocyturia on days $7-14$ & $3(10 \%)$ & $7(23 \%)$ & $\mathrm{p} \leq 0.05$
\end{tabular}

\section{Recurrence rate of stone formation within one year after ESWL}

Within one-year patient follow-up, recurrent stone formation after elimination of calculi from the urinary tracts was detected in 2 patients in the control group and no cases in the treatment group. However, due to the small number of studied events, it is impossible to talk about the reliability of differences in relation to the incidence of recurrent stone formation between the groups.

\section{Discussion}

Urolithiasis is a common and economically important disease characterized by formation of calculi (chemically various) in different parts of the urinary system. Despite the steady increase in the prevalence rate of this disease, the main emphasis in modern medicine is to improve methods of calculi removal and, to a lesser extent, conservative treatment [13, 14]. However, combination of these two approaches not only could increase the efficacy of calculi removal techniques but also prevent recurrence of stone formation $[15,16]$. The drug Canephron $\mathrm{N}$ fits well for the role of one of the major herbal components in the complex conservative UL treatment. This medical drug consists of a fixed combination of herbal components standardized by the composition of key active ingredients of herbs: centaury, lovage root and medical rosemary leaves. Such combined composition provides a complex effect on the kidneys and the urinary tracts that is expressed in a moderate diuretic [11, 17] and spasmolytic action [18] associated with the ability of the study drug to improve urodynamics and contribute to faster elimination of calculi $[19,20]$. During this study, more rapid elimination of calculi fragments from the urinary tracts was also observed. At the end of the second week after ESWL, the percentage of patients with complete elimination was by $20.8 \%$ higher in the treatment group than in the control group. Also, due to these properties, there were fewer cases (by $46.5 \%$ ) of lumbar pain or abdominal discomfort during elimination of disintegrated stone fragments in the treatment group. Anti-inflammatory action of herbal components in Canephron N [11] is of great importance, which contributes to rapid regression of consequences of the urinary tract mucosa injury and eradication of leukocyturia. This is supported by data of our study when we observed that the frequency of leukocyturia in the treatment group was $56.5 \%$ less than in the control group. Furthermore, it is very important for treatment goals that Canephron $\mathrm{N}$ has the ability to inhibit pathogenetic factor of urinary system pathogens which helps to prevent the occurrence of inflammatory process in the urinary tracts during elimination of urinary calculi fragments. With respect to prevention of recurrent stone formation, the ability of Canephron $\mathrm{N}$ to influence the key non-specific factors of stone formation is of great value: urine saturation with 
crystal-forming substances, increase in the concentration of magnesium ions in urine (natural inhibitor of crystallisation), influence on the infectious and inflammatory factors of urinary calculi formation. Therefore, it is clear that the use of Canephron $\mathrm{N}$ in the complex therapy following ESWL accelerates elimination of fragments of disintegrated calculi from the urinary tracts regardless of the level of their original location and reduces the number of such complications as lower abdominal pain and discomfort, renal colic attacks.

\section{Conclusion}

1. Canephron $\mathrm{N}$ is effective and safe for the treatment of patients with urolithiasis including those treated with extracorporeal shock wave lithotripsy.

2. Treatment with Canephron $\mathrm{N}$ contributes to faster and safer elimination of destructed calculi fragments and reduces risk.

3. Treatment with Canephron $\mathrm{N}$ for 6 months contributes to prevent of recurrent stone formation.

\section{Declarations/Limitations}

A limitation of this study is the lack of blinding and a limited number of patients. The latter circumstance does not allow to achieve a statistically significant difference between the groups according to some of the study parameters, namely: the incidence of renal colic attacks during elimination of urinary calculi fragments, the incidence of recurrent stone formation within one year after ESWL.

\section{Ethical approval and consent to participate}

The study was conducted in accordance with the Declaration of Helsinki [11] and the ICH Harmonized Tripartite Guideline for Good Clinical Practice (CPMP/ICH/135/95) [12]. Before the enrolment of the first patient, the study protocol was approved by the local Ethics Committee. Written informed consent to all study activities was obtained from all patients.

\section{Conflict of interest}

None. The study was conducted upon the initiative of the investigator. Bionorica SE has provided the necessary information support in the form of a scientific dossier on the drug Canephron $\mathrm{N}$ and scientific evidence on the problem.

\section{References}

[1] Keoghane, S., Walmsley, B., Hodgson, D. (2009). The natural history of untreated renal tract calculi. BJU International, 105 (12), 1627-1629. doi: http://doi.org/10.1111/j.1464-410x.2010.09389.x

[2] Aliaev, Iu. H., Amosov, A. V., Hazimiev, M. A. (2010). Ultrasonic methods of functional diagnostics in urological practice. Moscow:"R. Valent".

[3] Alyaev, Y., Rudenko, V. (2016). Current aspects of drug treatment of patients with urolithiasis. Efective Pharmacotherapy. Urology and Nephrology, 5 (41), 10-16.

[4] Cherepanova, E., Dzeranov, N. (2014). Metaphilic of urolithiasis in outpatient conditions. Health of Men, 2 (49), 21-25.

[5] Davidov, M. I., Igoshev, A. M. (2015). The effect of the herbal preparation Canefron ${ }^{\circledR} H$ on the results of distance shock-wave lithotripsy. Health Man, 4 (55), 96-100.

[6] Ceban, E. (2012). Efficacy of a fixed combination of Centaurii herba, Levistici radix and Rosmarini folium in urinary lithiasis. Zeitschrift Für Phytotherapie, 33 (1), 19-23. doi: http://doi.org/ $10.1055 / \mathrm{s}-0031-1286040$

[7] Tiselius, H-G., Alken, P., Buck, C., Gallucci, M., Knoll, T., Sarica, K., Türk, Chr. (2009). EAU Guedlines on urolithiasis. European Association of Urology, 116.

[8] Kok, D. J. (2015). The preventive treatment of recurrent stone-formation: how can we improve compliance in the treatment of patients with recurrent stone disease? Urolithiasis, 44 (1), 83-90. doi: http:// doi.org/10.1007/s00240-015-0842-9 
[9] Alyaev, Y., Rudenko, V. (2012). Herbal preparation Canephron N in the treatment of patients with urolithiasis. Urology, 6, 22-25.

[10] Gaibulaev, A., Kariev, S. (2012). Effect of long-term Canephron N treatment on urinary risk factors associated with idiopathic calcium urolithiasis. Springer Medizin.

[11] Naber, K. (2013). Efficacy and safety of the phytotherapeutic drug Canephron N in prevention and treatment of urogenital and gestational disease: review of clinical experience in Eastern Europe and Central Asia. Research and Reports in Urology, 5, 39-46. doi: http://doi.org/10.2147/rru.s39288

[12] Grigoryan, V., Amosov, A. (2011). The use of Canephron H in urolithiasis. RMJ, 16, 1033.

[13] Alelign, T., Petros, B. (2018). Kidney Stone Disease: An Update on Current Concepts. Advances in Urology, 2018, 1-12. doi: http://doi.org/10.1155/2018/3068365

[14] Strohmaier, W. L. (2000). Volkswirtschaftliche Aspekte des Harnsteinleidens und der Harnsteinmetaphylaxe. Der Urologe A, 39 (2), 166-170. doi: http://doi.org/10.1007/s001200050026

[15] Yeni, E et. al. (2003) 2 EULIS Meeting (The 10-th European Symposium on Urolithiasis). Istanbul, 348.

[16] Trinchieri, A. (2006). Epidemiological trends in urolithiasis: impact on our health care systems. Urological Research, 34 (2), 151-156. doi: http://doi.org/10.1007/s00240-005-0029-x

[17] Kumarasamy, Y., Nahar, L., Sarker, S. (2003). Bioactivity of gentiopicroside from the aerial parts of Centaurium erythraea. Fitoterapia, 74 (1-2), 151-154. doi: http://doi.org/10.1016/s0367-326x(02)00319-2

[18] Ukhal, M., Gabchak, R. (2010). Use of drug Canephron N in complex with SPA -therapy in patients with urolithiasis. The health of man, 4, 117-121.

[19] Ukhal, M., Malomuzh, O. (2013). Modern possibilities of phytotherapy in the postoperative rehabilitation treatment of patients with urolithiasis complicated by chronic pyelonephritis. Urology, Andrology, Nephrology. Kharkiv, 196-200.

[20] Gracza, L., Koch, H., Löffler, E. (1985). Über biochemisch-pharmakologische Untersuchungen pflanzlicher Arzneistoffe, 1. Mitt. Isolierung von Rosmarinsäure aus Symphytum officinale und ihre anti-inflammatorische Wirksamkeit in einem In-vitro-Modell. Archiv Der Pharmazie, 318 (12), 1090-1095. doi: http://doi.org/10.1002/ardp.19853181207 